\title{
ERP Training and Evaluation: ERP Life-Cycle Approach to End-Users' Characterization and Competency Building in the Context of an Oil \& Gas Company
}

\author{
Fayez Ahmad Albadri ${ }^{1}$ and Salam Abdallah ${ }^{2}$ \\ ${ }^{1}$ ADMA-OPCO, Abu Dhabi, UAE \\ ${ }^{2}$ Abu Dhabi University, Abu Dhabi, UAE
}

\begin{abstract}
This paper highlights the criticality of the 'End-Users' factor to the success or failure of the ERP venture. This descriptive case highlights the ineffectiveness of the current approaches to ERP end-users' "training and competency building", that are commonly applied in ERP implementations. We propose as an alternative, a new structured approach that redefines the traditional role of "ERP Training" from isolated implementation project activities concerned with introducing end-users to "how to" use ERP applications to an integral part of a comprehensive "knowledge \& change management" strategy that advocates a holistic life-cycle approach to managing ERP Critical Success Factors (CSF).

The investigation benefits from the "iceberg competency model", the "training management cycle", and "Kirk-Patrik's evaluation model" as the theoretical basis and context for drawing a comparison of the suitability and effectiveness of training approaches adopted in major ERP implementations in UAE. The proposed approach, which is built around 'end-user characterization' as the main input into 'competency building' is flexible enough to plug into standard ERP methodologies and may be projected throughout the ERP life-cycle. The end-users characterization and competency building approach (EUCCB) is expected to contribute to healthy levels of ERP usage and utilization that leads to positive business gains and return on investment.
\end{abstract}

Keywords: ERP, Training, Competency Building

\section{Background: Managing ERP Projects}

Organizations of all sizes, profits or nonprofits have adopted one form or another of enterprise resource planning applications (ERP). ERP systems are increasingly becoming a business enabler for organizations to remain successful and competitive in this turbulent and networked environment. ERP systems are enterprise applications affecting many aspects of the organization both internally and externally. Therefore, successful ERP adoption and its effective usage and utilisation are critical to the success of the organization's performance and survival. ERP implementation can be viewed as an organizational transformation endeavours, it imposes socio-technical transformation of the organization and it involves a large number of stakeholders who may influence the success or failure of an ERP project. Boonstra (2006) in his study on the influence of stakeholder on ERP implementation argues that stakeholders have different interpretation of ERP systems and this may lead to differences about priorities and ways of implementations. Stakeholders are affected by the previous experience, interests, self-images and prospects and views.

A typical ERP application may consist of 1,000 modules and 10,000 application program (Steven, 1997). The cost for deploying an ERP can range from 3 million to one billion dollar depending on the company's size, and the implementation may last up to 4 years (Chen, 2001; Weston, 2001). ERP projects can take years to implement and like other IT projects they are subject to budget over-runs, delayed

Copyright (C) 2010 Fayez Ahmad Albadri and Salam Abdallah. This is an open access article distributed under the Creative Commons Attribution License unported 3.0, which permits unrestricted use, distribution, and reproduction in any medium, provided that original work is properly cited. The article is a reprint from a 2009 article. Contact author: Fayez Ahmad Albadri. E-mail: falbadri@adma.ae 
deliveries and as a fatal consequence falling short of meeting expectations or abandoning the project altogether. Trunick (1999) states that only 40 percent of ERP implementations are effective and 20 percent have been abandoned. Numbers of other studies have argued that ERP failures have been reported more than 50 percent and 60 to 90 percent are not performing as expected (Scheer and Habermmann, 2000; Sarker and Lee, 2003; Escalle et. al, 1999, Trunick, 1999, Ptak and Shragenhe, 1999; SOh et. al. 2000). No one seems to be immune from an ERP project failure, Dell for example after two years they have abandoned their ERP project because of incompatibility with their business model. Others like FoxMeyer, did not have the time to abandon their ERP project instead they filed for bankruptcy in 1996 (Davenport, 1998).

Interestingly, most often managers view ERP projects failures as technical while in fact at $50 \%$ of the failures are attributed to people related issues such as resistance to change, lack of appropriate training, awareness, and / or understanding the organization culture. The organization culture is probably the most difficult hurdle in the implementation of an ERP since it involves a complex marriage between people personal values, habits, skills and the business processes and how staffs are viewed. Ward et. al (2005) argues that organizational issues during enterprise applications implementations are more difficult to resolve than the technical ones.

ERP research continued to attract practitioners and academics interest to determine ways to engineer successful ERP implementations. Research into ERP at any given time of its lifecycle is considered including, evaluation of software, effective user training or determining critical success factors.

For a compilation of critical success factors, see Sherry and Martin (2007) for 26 categories of CSF grouped by either strategic or tactical. The most reported CSF is top management commitment support (strategic), change management (strategic), BPR and software configuration (tactical), Training and Job design (tactical). An overstressed issue in the ERP implementation is to view ERP project as a business rather than technical solution. Reasons for failure have been attributed to poor planning, lack of user involvement and training, delays, over budgets and lack of skills (Summer, 2000; Umble and Umble, 2002, Wright and Wright, 2002). Resistance to change is also another main contributor to project failures; a study of 186 companies that implement enterprise system revealed that the second most important contributor to project overruns is resistance to change and it is the fourth factors that limit successful systems adoption (Cook et. al., 1998).

The size of the organization also matters; Sanna et. al (2007) argue that different sizes of organizations should not be treated as one homogeneous group when constraints of ERP systems adoption are investigated.

From the literature review and the authors' experiences, we found that change management and training are important critical success factors in an ERP project and should they be appropriately attended to, they can resolve important common problems faced by ERP project. Unfortunately, although some organizations recognise the importance of endusers' training, often many companies treat it as a single step activity in the overall ERP implementation project. The subject of 'ERP training and evaluation' is evidently an under researched area although there is a greater need for such studies since managers are always on the lookout for new easy approach to evaluate their successes.

\section{Training and Evaluation}

As mentioned earlier ERP training is one of the major determinants of successful ERP implementation. ERP training is important, but when it comes to budget, it is usually neglected or cut when projects are overrun. This imposes a challenge on the training to find innovative ways to be more effective and efficient. In addition, to the large amount of ERP investments in terms of human and financial efforts, executives require evaluation of the success of the implemented systems. Although training is generally related to users' ability to use the ERP applications, a more comprehensive view of the subject considers 'people' issues which are evident throughout the life cycle of ERP including (pre-implementation, implementation and post implementation). People issues are recognized as important yet inadequately addressed.

ERP implementation methodologies usually incorporate training as one of their components, often designed on the basis of instructor-led classroom training and delivered towards the conclusion of the project. We contend this approach to training is inadequate because it does not address all the relevant issues and are not effective in preparing users to adopt and make effective use of the system. We need to consider an alternative holistic approach that is 
more result-driven, user-focused solution and to provide users with the competencies needed to drive value in the organization investment.

\section{ERP Training in the context of UAE}

Three main ERP training approaches have been identified in a review of 22 ERP projects implemented in the United Arab Emirates (UAE), between 1998 and 2004. The review included major organization in the Oil \& Gas, Utility and Manufacturing industries. The review indicated that they have used one of three main approaches to address users' preparedness for using the ERP system, namely; 1) The traditional HRD approach, 2) The ERP methodologyprescribed approach and 3) An integrated ERP end-user characterization based competency building approach.

\section{Traditional HRD Approach}

The traditional Human Resources Development (HRD) approach is a simple, subjective, nonrobust, conservative, instructor-led class type where users' training requirements are superficially validated at job description level to reach gaps and to justify training expenditure. The approach is virtually consistently limited in effectiveness and suitability to ERP projects. The approach is generally vulnerable to influence by internal business politics, usually in favor of high ranking employees (management) without a proper established need. The approach is mainly concerned with the delivery of specific knowledge points without much consideration to users' perceptions and attitudinal behavioural.

\section{ERP methodology- Training approach}

This approach corresponds to the sum of training activities included as component of ERP implementation methodologies that are primarily concerned with preparing end-users to use and utilize the ERP applications and tools. Almost all ERP implementation methodologies have a dedicated end-user training component which may vary in scope and details to include end-users' awareness and change management. Methodologies such as SAP's ASAP, Deloitte \& Touch FastTrack, Oracle's AIM and IBM's PRACTICOM also define user training as a main project deliverable. There is a strong evidence from most ERP projects that have applied such training style that this instructor-led class, vendor designed and delivered training tend to lack in business depth and relevance in both content and business, often ill-timed and quality compromised due to project time and cost constraints. In many cases, the gain from this training is marginal warranting the need in many cases to be followed by refresher-training, coaching and 1-1 mentoring in the post roll-out.

\section{End-User Characterization based competency-building approach}

This approach refers to a more holistic and creative approach that is more comprehensive in addressing end-users competencies including knowledge, perceptions and attitudinal behaviour to ensure end-users' awareness of the business value of the system, understanding of their role as end-users, and perceiving the system usefulness at both organizational and individual levels. This is achieved through active involvement and partnering with end-users to play an active role throughout the life-cycle of the ERP project staring with ERP selection in the pre-implementation phase, going through implementation phase and most importantly during the post-implementation phase. The approach is user-focused, flexible and diversified in terms of instructional design, role of users as a SMEs and usage of different technologies for delivery.

\section{Training Cycle and Evaluation Methods}

\section{The Training Cycle}

There are numerous versions of training / learning cycle definition in the literature, however a typical cycle would include as a minimum the following processes: 1) Identification of training need (ITN), 2) Design of training solutions, 3) Delivery of training, 4) Applications of training and 5) Evaluation of training solution.

1) Identification of training needs: This is the process of identifying training needs and requirements and the target audience (endusers). As early as this stage the impact success criteria could be decided upon. The main outputs of this stage are answers to why the training is needed, what is the expected outcome of the training and its impact. (How to measure whether the training meets the identified need)

2) Design of training solutions: This process covers the planning, design and development of relevant training material. It is important in this stage to ensure that the training design solution approach is consistently adopted. The training solution design may include different delivery techniques including conventional class training, coaching or e-learning.

3) Delivery of training solutions: This process of the training cycle is concerned with the effectiveness of the training delivery to ensure success of the learning process and knowledge transfer. This will involve the selection of most appropriate format and methods to meet training needs. 
4) Application of training: This is concerned with applying learning outcomes and ensuring learning reinforcement through practice. This is specifically relevant to monitoring and reviewing the progress of individual learners.

5) Evaluation of training solutions: This deals with the collection, analysis and presentation of information to establish improvement in performance that results from this. The evaluation and assessment of the learning program is used to introduce improvements.

\section{The Iceberg Competency}

Competency can be defined as the technical capability which enables people to deliver superior performance in a given job, role, or situation. Competency can be acquired through talent, experience or training, which are, which are important and needed because they represent the best way to understand, observe and predict people's performance. Competencies are only valid if they are visible, accessible and are linked to meaningful life outcomes describing how people should perform (Hay Group, 2003).

Different levels and types of competencies are formed through individual and organization's knowledge, skills and abilities and provide a framework for measuring performance. The "iceberg" Competency model (Fig 1), shows proposed levels of competency illustrating that while some elements above the surface (technical / hard competencies) are identifiable, measurable and known to others, others (behavioural attitudinal competencies) are usually unknown to others, more difficult to detect and measure, yet of significant value. (De Wit and Meter, 2004).

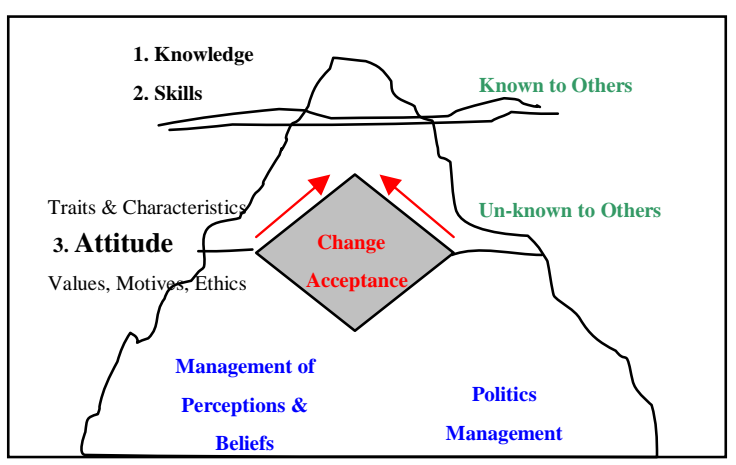

Fig 1 Iceberg Competency Model
The competency iceberg model, at an individual level defines competency as a cluster of:

Knowledge: (business processes, company policies)

Skills: (How to use system to make procure goods and services)

Attitude: Behaviour, articulated perceptions. (Competitiveness, Customer-Focus)

Personal characteristics: that influence job performance (Carefulness, Responsibility, ethics)

\section{The Kirk-Patrick's Evaluation Model}

Donald Kirkpatrick's Training Programs Evaluation Model is one of the most widely used and most popular models for the training evaluation. Although criticized, the four-level model is considered across training communities as an industry standard. The four levels of Kirkpatrick's evaluation model measure:

- Reaction of trainees (what they thought and felt about the training)

- Learning (The resulting increase in knowledge or capability)

- Behaviour (The extent of behaviour and capability improvement and implementation/application)

- Results (The effects on the business or environment resulting from the trainee's performance)

These four levels should be applied comprehensively and together they should lead to meaningful learning evaluation within organization. Table (1) outlines the main characteristics of the four evaluation levels, provides examples of evaluation tools and comments on its relevance and practicability (Kirk-Patrick, 1976) 
Table 1 Overview of Kirk-Patrick's model

\begin{tabular}{|c|c|c|c|}
\hline $\begin{array}{c}\text { Level/ } \\
\text { Evaluation } \\
\text { type }\end{array}$ & Evaluation description & Evaluation tools \& methods & $\begin{array}{c}\text { Relevance \& } \\
\text { Practicability }\end{array}$ \\
\hline $\begin{array}{c}\text { Level 1 } \\
\text { Reaction }\end{array}$ & $\begin{array}{c}\text { Gauges the trainees } \\
\text { feelings about the training } \\
\text { course and the learning } \\
\text { experience }\end{array}$ & $\begin{array}{c}\text { Feedback forms Verbal feedback } \\
\text { post training surveys }\end{array}$ & $\begin{array}{c}\text { Quick - Easy to obtain - } \\
\text { Not expensive }\end{array}$ \\
\hline $\begin{array}{c}\text { Level 2 } \\
\text { Learning }\end{array}$ & $\begin{array}{c}\text { Measures the increase in } \\
\text { the trainees knowledge }\end{array}$ & $\begin{array}{c}\text { Assessments or tests before and } \\
\text { after the training - interview or } \\
\text { observation }\end{array}$ & $\begin{array}{c}\text { Simple to set up; Easy for } \\
\text { quantifiable skills - Less } \\
\text { easy for complex learning }\end{array}$ \\
\hline $\begin{array}{c}\text { Level 3 } \\
\text { Behaviour }\end{array}$ & $\begin{array}{c}\text { Assesses the extent of } \\
\text { applied learning on the job }\end{array}$ & $\begin{array}{c}\text { Observation and Interview over } \\
\text { of change, and sustainability of }\end{array}$ & $\begin{array}{c}\text { Measurement of changed } \\
\text { behaviour Cooperation of } \\
\text { line- managers }\end{array}$ \\
\hline $\begin{array}{c}\text { Level 4 } \\
\text { Results }\end{array}$ & $\begin{array}{c}\text { Estimate the impact on the } \\
\text { business by the trainee }\end{array}$ & $\begin{array}{c}\text { Measures are already in place via } \\
\text { normal management systems and } \\
\text { reporting - the challenge is to relate } \\
\text { to the trainee }\end{array}$ & $\begin{array}{c}\text { inlike whole organisation } \\
\text { indually not difficult; } \\
\text { Process must attribute } \\
\text { clear accountabilities }\end{array}$ \\
\hline
\end{tabular}

The following section describes the case context and the components and features of the approach adopted by the Oil and Gas Company (OGCO) to manage its ERP end-users characterization and competency building. The approach has its origins and theoretical underpinning in the relevant training cycle, competency model and Kirk-Patrick's Evaluation model all of which were defined and characterized in an earlier part of this paper. The ERP End-User Characterization and Competency (EUCCB) approach was adopted by OGCO as the vehicle to realize the sought business gains from the ERP system by systemically elevating end-users' knowledge, skills and attitudinal competencies leading to improved system acceptance and effective usage and utilization. Also, in the following sections, we review the main components and features of the adopted approach (EUCCB) and review its results.

5. Case Study: The Oil \& Gas Company (OGCO) The organization was a major Oil and as producer and exporter company. Since its establishment, it had developed substantial business interests in all sectors of the Oil and Gas industries including exploration, production and other products. The organization structure was composed of business and support services divisions. The business divisions were concerned with the areas of exploration, production, refining and other services, whilst the support services divisions covered the areas of human resources, administration, finance, and management.

The organization (OGCO) embarked on a major project to replace its legacy system by state of the art integrated suite of ERP applications to support substantial part of the company's business function and processes. The selection of the system was reached after an extensive package evaluation carried out by a team of participants from different business areas.

The project's main goals included the establishment of a single centralized repository for assets, materials and maintenance-related information and to utilize the best practice capabilities of the chosen system with minimum customization. The project duration was 12 months, with project procedures being derived from a standard ERP implementation methodology. The project major phases were analysis and requirements definition, design, development and implementation. 
Alerted by reported ERP failures and recognizing the importance of the 'end-users' factor to the success of the ERP system in the company, senior management has approved the creation of a training advisory as part of ERP support team to specifically to manage endusers' issues throughout the life of the ERP system.

EUCCB Approach: Components and Features The definition of the main components of the adopted model represent proven best practices and have their links as mentioned before to established theories and models pertinent to process change, learning and training evaluation. The EUCCB comprise the following components:

- Training \& Change management Strategy

- Training Cycle Processes: Identification, Design, Delivery, Application and Evaluation

- Training Programming: Planning \& Management

- Training \& Evaluation Tools \& Methods

The EUCCB approach was adopted to provide the mechanism and a guiding roadmap for planning and managing relevant programs to resolve ERP end-users' system acceptance, perception and knowledge issues in the post implementation phase which was anticipated to extend over 10-15 years. A summary of the main activities undertaken by the support team guided by EUCCB is provided later on this section. The EUCCB approach had also adopted a number of quality attributes, namely, comprehensiveness, integration, continuity, diversification and reflective. The attributes described below- guided us also in designing the tools to deal with complex environment of ERP to ensure success in terms of system acceptance, usage and utilization.

a) Comprehensive (structured, modular and business aligned): The EUCCB approach is not training methodology guiding the progress of training ERP end-users on how to use the new systems in isolation of the business strategic, tactical and operational considerations. It is rather a comprehensive approach with components addressing important aspects pertaining to the 'human' component of ERP including end-users' perceptions, attitudes, knowledge gaps and competencies, guided by a strategy with well defined objectives and goals, from different business perspectives; administrative, managerial and technical. It also sets clearly the roles and relationships between all involved parties.

b) Integrated (integrates ERP planning, management and control): The EUCCB approach integrates training and competency building principles, concepts and practices tightly into the ERP planning and management. Standard training and competency building activities such as end-user characterization, training needs identification, content design, instructional design, instructional delivery and evaluation are woven into the planning, control and management of ERP system.

c) Continuous (applicable throughout the ERP Life-Cycle): The EUCCB approach advocates continuity in managing end-user issues such as attitudes, perceptions, knowledge, and skills throughout the ERP life-cycle including; 1) ERP Pre-Implementation, 2) ERP Implementation Phase and 3) ERP Post-Implementation Phase. Although the prime focus of the approach is mainly concerned with the ERP implementation phase but is also concerned with the links to the other two phases at both ends to ensure success is achieved. After all, the context of concern is to achieve the planned return on investment, which is outside the boundaries of the implementation phase.

d) Diversified (adopts suitable methods, tools and technologies): The EUCCB approach is flexible in terms selecting methods, tools and technologies that are appropriate and fitting to the situation on hand considering; Target audience, Business Culture, Organizations specifics, ERP environment, and the prevalent nature of the training subject. These include; instructor-led classroom training, online webbased training, e-learning, computer based training, mentoring, coaching etc.

e) Reflective (enter a learning cycle): The EUCCB is systemic in approach where it attempts to learn from every action that has been taken in the process of the ERP implementation and attempt to learn and improve any future actions (Usually, conducted during formal and informal meetings).

The following describes the main EUCCB components, OGCOs actions and the main results and deliverables:

EUCCB Component 1: Training \& Change Management Strategy

OGCOs Action: A strategy was formulated to address ERP end-user issues (in the postimplementation phase) at short, medium and long term. The strategy highlighted the strategic nature of the ERP in the company and the criticality of the 'human' factor to the success of the ERP in the company and to the realization of business benefits and ROI. The strategy emphasized end-user characterization as the basis for competency building program. The strategy provided guidelines for the planning and management of training and change management programs. It has referred to the 
training development cycle, the evaluation methods and tools to implement and review the strategy and the associated programs. The strategy emphasized the alignment of the training strategy with the company's business goal. The strategy calls for the utilization of different types of training, coaching, mentoring, awareness and to utilize technology to achieve goals.

Deliverables / Results: Strategy document was reviewed, updated and approved by management.

EUCCB Component 2: Training Programming: Planning \& Management

OGCOs Action: A training environment / facilities were created - a copy of the ERP production was setup to use for training purpose (without disrupting operations) in agreement with ITD to refresh on monthly basis. Special access accounts were arranged for use by trainees during the training and for posttraining practice.

A training coordinator assigned for administration of the training program and a representative from every business division to help in training analysis and in the nomination of trainees to different course. Training schedules were dispatched on monthly basis to divisions' representatives to nominate trainees for course. This network was also actively involved in site visits, divisional awareness sessions and workshops. A training register was created, Different attendance, assessment forms, tests, questionnaires were prepared. Weekly and monthly reports formats were prepared.

Deliverables / Results: Procedure, forms registers, schedules, programs, plans, reports, register, Training ERP region

EUCCB Component 3.1: Training Cycle Processes: Identification, Design, Delivery, Application and Evaluation

OGCOs Action: The training cycle guided the end-user characterization and competency maps -and the identification of training needs through meetings and workshops involving management and ERP end-users. Subject Matter Experts from different business areas were designated to help in the content and instructional design (each course had a selling ERP awareness component, a business knowledge component and a step-by-step ERP application 'how-to' scenarios. Different training modules and courses were developed and copied on CDs rather than paper to give away. A number of competent resources from the support team were selected to use in a pool of trainees to deliver the training course. Quick Reference guides summarizing different training scenarios were deposited on the intranet and made accessible to all end-users- feedback assessment forms were used at the end of the training sessions to indicate trainees reaction and feeling about the course, the instructor, the material and the training environment- pretraining and post-training test were also used to gauge level of knowledge. Regular evaluation and review of the training course content and duration were made on basis of trainees' feedback and reactions.

EUCCB Component 3.2: Change Management OGCOs Action: End-users attitudinal behaviour and perceptions related programs: awareness programs - site visits- newsletter - use different media for awareness- certification - rewards motives -management support.

Deliverables / Results: Training material for different course - Web-accessible QuickReference - Guide - Assessment forms - Pretraining tests - Post-training tests- Evaluation forms - Reports

EUCCB Component 4: Training and Evaluation Tools and Methods

OGCOs Action: Instructor-led classes Coaching, Mentoring, 1-1 management sessions, Train-the-Trainer, Computer Based Training, Recorded training macros, E-Learning, Web Based classes

Deliverables / Results: Classes, training scenarios recorded macros- web guides Trainees feedback Assessments - Questionnaires - Interviews - online survey - Tests certifications Rewards- Motives

Use of different Evaluation methods and tools

6. Results: EUCCB-based Training and Change Management Programs at OGCO

Three years into the post-rollout stage of the ERP system in OGCO, the support team has successfully contributed to improve end-users' attitudes, perception and acceptance of the ERP applications leading to improved levels of system applications usage and utilization. Following is a summarized list of outcomes providing evidence of tangible positive resulting from the adopted approach. And, they may be viewed as performance indicators:

EUCCB Component 1: Training \& Change management Strategy

Achievement: The training and change management strategy (revised version 3) has successfully ensured the alignment of the programs to the business goals and has provided guidelines to the quality, standards and best practice processes used in the implementation of the training approach. Numerous quick reference guides are deposited on the web and are accessible by end-users through the web 
EUCCB Component 2: Training Programming: Planning \& Management

Achievement: Skills were audited participants End-users reactions and perceptions consolidated in a database and regularly analysed and acted upon.

EUCCB Component 3: Training Cycle Processes:

Achievement: An elaborated end-user characterization is used as basis for the competency building programs.

EUCCB Component 4: Training Evaluation Tools \& Methods

Achievement:

- A foundation ERP training course and ten different specialized courses were designed, developed, delivered and regularly modified based on end-users reactions and feedback (exclusively internal resources)

- Several training scenarios were on recorded macros accessible to trainees

- Nearly 1400 trainees attended a total of 150 training sessions both on-site and off-site

- Nearly 30 'ERP Monitor' management reports and bulletins were issued with awareness messages, ERP knowledge tips and ERP news reaching out to hundreds of end-users.

- The trainees' feedback: 56\% very good, $40 \%$ good, $4 \%$ average $0 \%$ poor.

- Coaching and Train-the Trainer incorporated to complement formal classes.

- $\quad$ E-Learning feasibility study started and is planned for 2009.

- Pre-training and Post-training tests regularly used to evaluate the effectiveness of training

- A major on-line survey of two parts; 1) to gauge end-users perceptions by answering 20 multiple questions 2) to pinpoint knowledge weaknesses, was implemented and results discussed with management and divisions

- End-user audit including key users was conducted to observe the ability of trained users to transform their knowledge gain (by training) to action (use of the system application). This has helped us introducing more hands on practice additions to the training courses as well as 1-1 coaching.

- Survey results indicated increased end-user acceptance specifically among younger employees and those who attended training. Nearly $60 \%$ of participants are happy with the system, 15\% unhappy and $25 \%$ undecided. Suitable actions have been agreed for each of the groups.

- The knowledge tests provide clear evidence that those who attended training have higher results indicating the effectiveness of the training strategy and programs.
- The ERP support team has presented the survey findings to management who requested that the team launch a divisional awareness campaign to share the findings of the survey and agree jointly on suitable actions.

- Initial sessions of the awareness campaign (including four main divisions) indicate clear success in reaching out to users community, creating a positive environment of partnering and agreeing action for improvement including the introduction of management commitment for a rewarding program and certification.

\section{Conclusions}

It is clear that the adopted approach (EUCCB) through its structured, comprehensive, integrated approach has provided a useful integral framework for implementing a successful ERP end-users competency-building program with positive outcome. Considering the flexibility of the associated processes, the business relevance of the programs and the tangible gains accomplished through the exclusive use of internal company resources, it is suggested that such an approach can add real value to the outcome should it be adopted by organizations embarking on new ERP implementations.

Future research may offer the opportunity to have an elaborated investigation of the EUCCB approach to refine its components and features to validate its potential as a proven module that can be plugged onto standard ERP Implementation methodologies.

\section{References}

[1] Boonstra, A. "Interpreting an ERP implementation project form a stakeholder perspective", International Journal of Project Management, 2006, 24, pp. 38-52

[2] Chen, L.J. "Planning for ERP systems: Analysis and future trends". Business Process Management Journal, 2001, 7(5), pp. 67-77

[3] Cook, Dudley, and Peterson. "SAP implementation: Strategy and Results" The conference Board, 1998

[4] Davenport, T.H. "Putting the enterprise into the enterprise systems", Harvard Business Review. July/August 1998, pp. 121-131

[5] De Wit, B. and Meyer, R. "Strategy: Process, Content and Context". Thomson Learning, 2004

[6] Escalle, C.X. Cotteleer, M.J. and Austin R.D. "Enterprise Resource Planning (ERP)" 
Technology Note, Harvard Business School Publishing, 1999, Boston, MA.

[7] War, J., Hemingway, C. and Daniel, E. "A framework for addressing the organizational issues of enterprise systems implementation", Strategic Information Systems, 2005, 14, pp. 97119

[8] Hay-Group Working Paper (2003). High Competencies to Identify High Performers: An Overview of Basics. Retrieved Nov. 2008 from: http://www.haygroup.com/Downloads/uk/mis c/Competencies_and_high_performance.pdf

[9] Kirkpatrick, D. L. "Evaluation of training”. R. L. Craig "Training and development handbook: A guide to human resource development. New York: McGraw Hill, 1997

[10] Ptak, C.A. and Schragenheim, E. “ERP: Tools Technologies, and Applications for integrating the supply chain", CRC Press St Luci Press, Boca Raton, FL, 1999

[11] Laukkanen, S., Sarpola, S., and Hallikainen, P. "Enterprise size matters: Objectives and constraints of ERP adoption", Journal of Enterprise Information Management, 2007, 20(3), pp. 319-334

[12] Sarker, S. and Lee, A.S. "Using a case study to test the role of three key social enablers in ERP implementation", Information and Management, 2003, 40, 813-829

[13] Scheer, A. W. and Habermann, F. "Making ERP a success". Communication of ACM, 2000, 43(4), pp 57-61
[14] Finney, S. and Corbett, M. "ERP implementation: a complication and analysis of critical success factors", 2007, 13(3), pp. 329347

[15] Soh, C., Kien, S.S, and Tay Yap, J. "Culture fits and misfits: is ERP a universal solution?" Communications of the ACM, 2000, 43(4) pp. 4751

[16] Stevens, T. "Kodak focuses on ERP", Industry Week, 1997, 246(15), pp. 130-133

[17] Summer M. "Risk factors in enterprisewide/ERP projects", Journal of Information Technology, 2000, 15(4) pp. 317-27

[18] Trunick, P.A. "ERP: promise or pipe dream?" Transportation \& Distribution, 1999, 40(1), pp. 23-6

[19] Umble EJ, and Umble, MM. “Avoiding (ERP) implementation failure", Industrial Management, $2002,44(1)$, pp. $25-33$

[20] Weston, F.C. Jr. "ERP implementation and project management", Production and Inventory Management Journal, 2001, 43(3) pp. 75-80

[21] Wright, S. and Wight, A.M. "Information systems assurance for enterprises resources planning systems: implementation and unique risk consideration", Journal of Information Systems, 2000, 16 Sep, pp. 99-113 